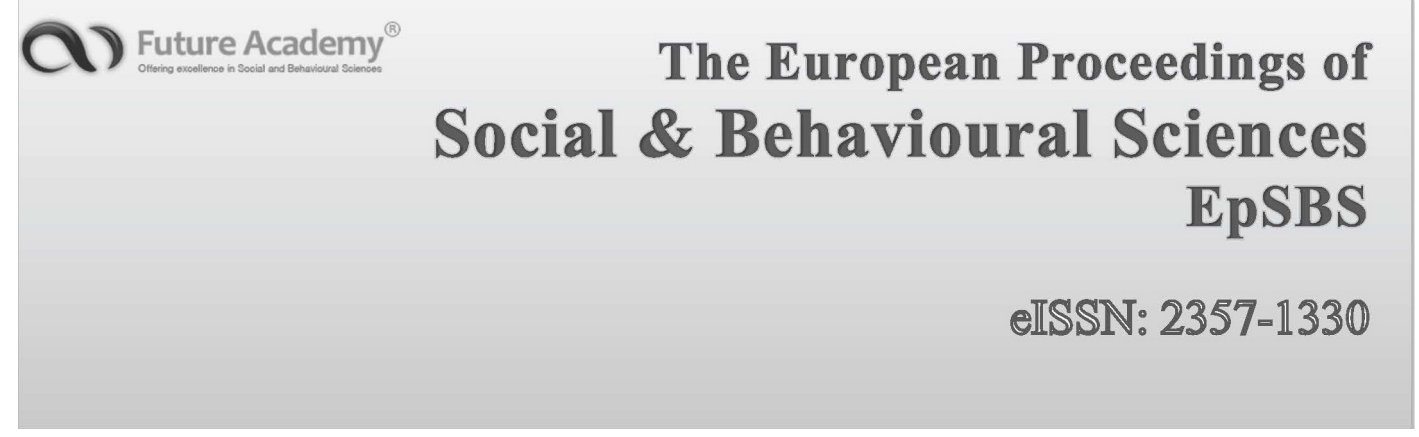

icH\&Hpsy $2016: 2^{\text {nd }}$ International Conference on Health and Health Psychology

\title{
Clinical Communication and Adverse Health Events: Literature Review
}

\author{
Manuela Ferreira $^{\mathrm{a}}$, Cláudia Brás ${ }^{\mathrm{b} *}$, Maria do Céu Barbieri ${ }^{\mathrm{c}}$ \\ * Corresponding author: Cláudia Brás, clau.bras@hotmail.com \\ ${ }^{a}$ Escola Superior de Saúde de Viseu-IPV, Rua R. D. João Crisóstomo Gomes de Almeida, Viseu, Portugal, \\ mmcferreira@gmail.com \\ ${ }^{b}$ Maternidade Bissaya Barreto- CHUC, Rua Augusta, Coimbra, Portugal, clau.bras@hotmail.com, ICBAS PhD student \\ ${ }^{c}$ Escola Superior de Enfermagem do Porto/ CINTESIS e Instituto Ciências Biomédicas Abel Salazar, Rua Dr. António \\ Bernardino de Almeida, Porto, Portugal, ceubarbieri@esenf.pt
}

\begin{abstract}
http://dx.doi.org/10.15405/epsbs.2016.07.02.32

Health institutions have an increased risk of occurrence of errors due to their diversity, specificity and volume of services, representing a great concern for health professionals whose main function is to protect the health and lives of their patients. We intend to identify a body of evidence, that shows what the most common adverse events are and what adverse events potentially arise from clinical miscommunication. We made an integrative literature review using the keywords "Adverse Events", "Patient Safety", "Communication". An inquiry on databases of PubMed, Web of Science, Scielo and CINAHL, in articles published between January 2010 and March 2016, was made; all available in Portuguese and English. Of the 216 articles that emerged, we selected eight that answered the research questions: what are the most common adverse events that have their origin in communication errors? Analyzing the selected studies, it appears that the most common adverse events arise in the context of obstetrics and pediatrics, in surgical contexts, in the continuity of care and related medication. Patient safety should be seen as a key component of quality in health care, with good management of the risk of fundamental error for the promotion of this security. The knowledge and understanding that communication failures are one of the main factors contributing to the occurrence of errors in the context of health care, allows the subsequent development of strategies to improve this process and thus ensure safer healthcare.
\end{abstract}

(C) 2016 Published by Future Academy www.FutureAcademy.org.uk

Keywords: Adverse events; patient safety; communication.

\section{Introduction}

The complexity of health care, organizational policies, environment, culture and relations culminate in the occurrence of adverse events with an impact on patients, families and society. Evidence has shown us that mistakes are a constant practice of health care and occur at any stage of the process. It is 
eISSN: 2357-1330

Selection \& Peer-review under responsibility of the Conference Organization Committee

indisputable that the occurrence of errors in the provision of health care create a constant concern for professionals, because their actions should focus on the philosophy of good practices. Sousa Uva, Serranheira, Milk \& Nunes (2011), report that "the incidence of adverse event rates in hospitals reach values ranging between $3.7 \%$ and $16.6 \%$ (with consequent clinical, economic and social impact), and of these the largest share (40\% to $70 \%)$ are considered preventable or avoidable "(p.13).

The patient safety issue has a strategic priority in Europe, as patients of health care services, it is essential to propose changes to reduce situations that conduce to the occurrence of adverse effects. This view of security, requires not only a focus on the individual factors, but also on the inter-relationships between individuals and their context, both in the immediate working environment and between organizations. The communication problems lead to disorders in team activities, leading professionals to blame each other for existing failures, causing emotional distress, interpersonal conflicts, operating and managing errors (Roque, 2012). Communication is an essential process in human relationships, as it constitutes a device of extremely important information on labour relations, involving patients, family members and health professionals. Failures at this level can be the cause of a decrease in the quality of care, errors in treatment and can also constitute a potential harm to patients.

\section{Problem Statement}

Health institutions present a risk of occurrence of errors due to their complexity and specificity of care. The gaps in communication enhance the processes of adverse health events. The Joint Commission on Accreditation of Healthcare Organizations, noted that $65 \%$ of sentinel events are associated to miscommunication (Fay Hillier, Regan, Gallagher \& Gordon, 2012).

\section{Research Questions}

For this study, we designed the following research question: What are the most common adverse events that have been originated by errors in communication?

\section{Purpose of the Study}

Currently, in healthcare, the large volume of scientific information points to the need for summaries, conclusions and guidelines based on a combination of results from multiple studies and can contribute to the consistency for the reasons for a clinical decision that is to evidence-based practice, and consequent improvement of practices (Pereira, Gaspar Reis, Barradas \& Noble, 2012). The purpose of this study is to gather a recent body of evidence that reflects the most common mistakes that have errors of communication in their origin.

\section{Research Methods}

We accomplished an integrative literature review defined as a method that aims to summarize results that are obtained in research in a topic or in a question, in a systematically, orderly and 
comprehensive way. It is called integrative because it provides further information on a subject / problem, therefor constituting a body of knowledge. Thus, the researcher can develop an integrative review for different purposes and can be directed to the definition of concepts, review of theories and methodological analysis of the included studies of a particular topic. For the construction of the integrative review it is necessary to go through six distinct stages, namely: identification of the research question; establishment of criteria for inclusion; definition of information to be extracted from selected studies; assessment of included studies; interpretation of results and presentation of the review (Mendes, Silveira \& Galvao, 2008). Following this approach, it was possible to identify the main studies to answer the research question: What are the most common adverse events that have their origin in communication errors? A research was executed across the terms: " Adverse Events ", " Patient Safety ", "Communication", obtaining as a result the following MeSH terms shown in Table 1.

Table 1. Keywords and MeSH Terms

\begin{tabular}{l}
\hline \multicolumn{1}{c}{ Patient safety Adverse events } \\
\hline MeSH Terms \\
"Safety Management"[Mesh] AND ("Patient Safety"[Mesh] AND "Communication \\
\hline
\end{tabular}

As inclusion criteria, studies, to answer the question of research published between January 2010 and March 2016, were established, available in Portuguese and English, from scientific databases. The scientific databases were PubMed, Web of Science, Scielo and CINAHL, identified as A1, A2, A3 and A4 respectively, as outlined in Table 2.

Table 2. Studies that have been recognized since the introduction of descriptors

\begin{tabular}{|c|c|c|c|}
\hline CODE & DATA BASE & KEYWORDS & RESULTS \\
\hline $\mathrm{A} 1$ & PubMed & $\begin{array}{c}\text { "Safety Management"[Mesh] AND } \\
\text { ("Patient Safety"[Mesh] AND } \\
\text { "Communication"[Mesh]) AND (Controlled } \\
\text { Clinical Trial[ptyp] OR Review[ptyp]) }\end{array}$ & 99 \\
\hline $\mathrm{A} 2$ & Web of Science & $\begin{array}{l}\text { "patient safety", AND "adverse events", " } \\
\text { communication" }\end{array}$ & 81 \\
\hline A3 & Scielo & $\begin{array}{l}\text { "patient safety " AND “adverse events } \\
\text { "AND "communication" }\end{array}$ & 8 \\
\hline A4 & CINAHL & $\begin{array}{c}\text { (patient safety) AND (adverse events) AND } \\
\text { (communication) AND year cluster:("2013" } \\
\text { OR "2010" OR "2011" OR "2012" OR } \\
\text { "2014") }\end{array}$ & 28 \\
\hline
\end{tabular}

In studies for research strategy emerged 216 articles. After reading the titles, 98 articles were selected. These articles were part of the criteria for analysis and after reading the summaries 32 articles were selected, for their content was of interest to this review. We obtained 10 articles that met the preestablished criteria, but we were only able to include 8 articles in the study, of which one we had access to the full text, presented in Table 3. 
Table 3. Results of studies in analysis

\begin{tabular}{|c|c|c|}
\hline REFERÊNCE & DOCUMENT TYPE & ABSTRACT \\
\hline $\begin{array}{c}\text { (Deering et al., 2011) } \\
\text { United States }\end{array}$ & Review article & $\begin{array}{l}\text { Adverse events in pediatric contexts } \\
\text { This article describes that most cases of perinatal deaths and } \\
\text { pediatric lesions are caused by problems with the culture of an } \\
\text { organization and communication failures. It mentions the } \\
\text { importance of a skills training program for health professionals in } \\
\text { communication and clarification of roles and mutual support. }\end{array}$ \\
\hline $\begin{array}{c}\text { (Alderman, 2012) } \\
\text { United States }\end{array}$ & Reflection Article & $\begin{array}{l}\text { Adverse events in obstetric contexts } \\
\text { This article states that in obstetrics, poor communication and } \\
\text { teamwork are causal factors of sentinel events. It refers to the } \\
\text { possibility of using simulation techniques as a teaching strategy to } \\
\text { improve communication skills and teamwork. }\end{array}$ \\
\hline $\begin{array}{c}\text { (Healey et al., 2010) } \\
\text { United Kingdom }\end{array}$ & Review article & $\begin{array}{l}\text { Adverse events in surgical contexts } \\
\text { This article mentions that communication failures are a major cause } \\
\text { of errors in surgery. Several researchers and practitioners have } \\
\text { developed different interventions to improve communication } \\
\text { preoperatively using checklists. }\end{array}$ \\
\hline $\begin{array}{c}\text { (Bohomol \& Tartali, 2013) } \\
\text { Brasil }\end{array}$ & Research Paper & $\begin{array}{l}\text { Adverse events in surgical contexts } \\
\text { Study of descriptiveness character with } 31 \text { nurses in the operating } \\
\text { room of a private hospital, which has shown the knowledge of the } \\
\text { nursing team about adverse events on patients of a surgical center, } \\
\text { pointing out possible causes for the occurrence of adverse events, } \\
\text { particularly at the level of communication. }\end{array}$ \\
\hline $\begin{array}{c}\text { (Mistry et al., 2010) } \\
\text { Canada }\end{array}$ & Research Paper & $\begin{array}{l}\text { Adverse events in the continuity of care } \\
\text { Quantitative and qualitative study aiming to identify a structured } \\
\text { process in times of handover that allows a direct exchange of more } \\
\text { accurate information among health professionals. It addresses the } \\
\text { need for data accuracy for the safety of the patient. }\end{array}$ \\
\hline $\begin{array}{c}\text { (Kerckhoffs et al., 2013) } \\
\text { United States }\end{array}$ & Research Paper & $\begin{array}{l}\text { Adverse events in the continuity of care } \\
\text { Prospective study with the target population of nursing and medical } \\
\text { professionals in an intensive care unit, using the model of Bow -Tie } \\
\text { to identify the existence of potential causes for critical events } \\
\text { specifically related to the transfer of information. }\end{array}$ \\
\hline $\begin{array}{c}\text { (Symons et al., 2013) } \\
\text { United Kingdom }\end{array}$ & Research Paper & $\begin{array}{l}\text { Adverse events with medication } \\
\text { An observational study of } 50 \text { patients undergoing surgery, } \\
\text { evaluating the frequency, severity and etiology of failure in the post- } \\
\text { operative care. A total of } 256 \text { faults were identified that occurred in } \\
\text { the process of care, the most common being those, related to the } \\
\text { prescription and administration of medication. }\end{array}$ \\
\hline $\begin{array}{c}\text { (Cox \& Butt, 2012) } \\
\text { United Kingdom }\end{array}$ & Review article & $\begin{array}{l}\text { Adverse events with medication } \\
\text { This article describes that the communication on drugs safety is } \\
\text { complex and often poorly executed. Failures in communication can } \\
\text { cause difficulties, recognizing that a common language among health } \\
\text { professionals should be designed to minimize the risks. }\end{array}$ \\
\hline
\end{tabular}


http://dx.doi.org/10.15405/epsbs.2016.07.02.32

eISSN: 2357-1330 / Corresponding Author: Cláudia Brás

Selection and peer-review under responsibility of the Organizing Committee of the conference

\section{Findings}

The analysis of the articles through critical and qualitative reading identified convergences allowing the following grouping by themes: adverse events in obstetric and pediatric contexts, adverse events in surgical contexts, adverse events in the continuity of care and related adverse events with medication. In Table 4 (below) the most mentioned contexts in which communication failures and adverse events occur, were related along the bibliography and presented succinctly in the areas of nursing and medicine.

Table 4. Summary of evidence - Communication as a source of adverse events in health

\begin{tabular}{l|l}
\hline Adverse events in obstetric and pediatric contexts & $\begin{array}{l}\text { (Deering et al., 2011) } \\
\text { (Alderman, 2012) }\end{array}$ \\
\hline Adverse events in surgical contexts & $\begin{array}{l}\text { (Healey et al., 2010) } \\
\text { (Bohomol \& Tartali, 2013) }\end{array}$ \\
\hline Adverse events in the continuity of care & (Mistry et al., 2010) \\
& (Kerckhoffs et al., 2013) \\
\hline Adverse events related with medication & $\begin{array}{l}\text { (Symons et al., 2013) } \\
\text { (Cox \& Butt, 2012) }\end{array}$ \\
\hline
\end{tabular}

\subsection{Adverse events in the obstetric and pediatric contexts}

The miscommunication and deficits in team work are the main cause of cases of sentinel events in obstetric specialty. According to Alderman (2012), childbirth is a multidisciplinary process involving nurses, obstetricians, anesthetists and pediatricians, and a process that itself can take hours, involving professionals from various shifts, and an increased risk of adverse events if the communication is not effective. In the context of a pediatric hospital, a study described a sentinel alert issued by the Joint Commission which revealed that the majority of deaths and injuries in the perinatal period are caused by fragile organization's safety culture and communication failures. Some common barriers to effective communication include the small number of team members, distractions, fatigue and different styles of communication. This study also clarifies the importance of a skills training program for health professionals in communication, clarification of roles and mutual support (Deering, Johnston, \& Colacchio, 2011).

\subsection{Adverse events in surgical contexts}

The authors refer to the operating room as an environment where the patient's injury is more likely to be a place with high levels of stress, high complexity and high risk, where the communication within a team can clearly fail. Communicational and organizational structures prove to be the greatest source of errors in this environment, and for this reason the authors suggest the creation of checklists to streamline the information processes (Healey, Nagpal, Moorthy, \& Vincent, 2010). In a study with patients undergoing surgery in Brazil, the authors report that $32.2 \%$ of nurses mentioned the lack of communication between elements of the health teams as one of the causes for the occurrence of adverse events, suggesting that quality care depends on effective communication (Bohomol \& Tartali, 2013). This is confirmed by the data from the events of an American Program Accreditation Report 
eISSN: 2357-1330

Selection \& Peer-review under responsibility of the Conference Organization Committee

where 843 events were recorded and the analysis showed that $533(63.2 \%)$ of these events were due to problems with communication in a surgical center.

\subsection{Adverse events in the continuity of care}

A huge flow of information, a large number of professionals from different teams and numerous interventions entail a constant need to update and exchange information. Some authors studied the optimization of transfers of patients, using specific methods and strategies involving patients and professionals to improve this communication process. Failures in these communication processes are recognized as potentially dangerous to the safety of patients and are associated to adverse events. An ineffective "handover" may lead to inappropriate treatment, increased health care costs, increased morbidity and mortality (Mistry, Toulany, Edmonds, \& Matlow, 2010). Other authors address this context of information transfer in a study by applying risk analysis methodology "Bow-Tie", noting that there are several barriers to patient safety, related with communication. With this method it is possible to get a general and clarified overview of the adverse scenarios as well as the identification of causes and consequences of the central point of the critical event (Kerckhoffs, van der Sluijs, Binnekade, \& Dongelmans,2013).

\subsection{Adverse events related to medication}

A study made by several authors has proven, that about $75 \%$ of the adverse events could have been prevented, being the most common related with the prescription and administration of medicines, whose origin in 54\% of cases relates to miscommunication (Symons, Almoudaris, Nagpal, Vincent, \& Moorthy, 2013). Other authors pored up on the issue of errors and adverse events resulting from failures related to the medication, referring to the lack of openness in communication between professionals and generating errors related adverse drug reactions (Cox \& Butt, 2012). The International Council of Nurses (2012) recognizes that nurses play a key role in the safety of the patient, in particular when regarding medication errors, remembering that nurses are often responsible for the detection and correction of errors committed by other professionals.

\section{Conclusions}

Adverse events are an undeniable reality in health care as a source of serious damage to patients, complications that can lead to death, suffering, impaired quality of life of the patients and their families. These events also involve social and economic costs in organizations and in society in general.

For the development of quality and safe care practices it is urgent to identify the causes of adverse events. This study shows us that communication processes are responsible for adverse events in various contexts of health by being complex and dynamic processes.

Communication is the basis of care and requires a high performance from the health teams, and hence, interpersonal conflicts arise and operational errors caused by the deficiency or lack of 
communication. Ineffective communication and differences in perceptions of communication between members of a team in the various scenarios of care practices create opportunities for committing errors.

We detected in this research that there are many times when communication cannot be effective, given the high-risk settings, environments with high levels of stress and where many professionals connect, such as surgical environments, pediatric and obstetric areas. The lack of information also increases the occurrence of errors during the transfer of patients in times of passing the shift and in times of prescription and administration of medication. Patient safety is a multidisciplinary responsibility, but it is the nurses who play a key role in the development of health care insurance, since nurses ensure the continuity of care and provide the most direct patient care, articulating its interventions with various professionals. The results of this research alert us, not only to the need to notify the errors, but also to identify the problems that caused the error and to implement the necessary changes, solving the inherent miscommunication issues to promote an improved quality of care.

\section{References}

Alderman, J. T. (2012). Using simulation to teach nursing students and licensed clinicians obstetric emergencies. MCN Am J Matern Child Nurs, 37(6), 394-400. doi:10.1097/NMC.0b013e318264bbe7

Bohomol, E., \& Tartali, J. d. A. (2013). Eventos adversos em pacientes cirúrgicos: conhecimento dos profissionais de enfermagem. Acta Paul Enferm, 26(4), 376-381. 373.

Cox, A. R., \& Butt, T. F. (2012). Adverse drug reactions: when the risk becomes a reality for patients. Drug Saf, 35(11), 977-981. doi:10.2165/11636140-000000000-00000

Deering, S., Johnston, L. C., \& Colacchio, K. (2011). Multidisciplinary teamwork and communication training. Semin Perinatol, 35(2), 89-96. doi:10.1053/j.semperi.2011.01.009

Fay-Hillier, T. M., Regan, R. V., \& Gallagher Gordon, M. (2012). Communication and Patient Safety in Simulation for Mental Health Nursing Education. Issues in Mental Health Nursing, 33(11), 718-726. doi:10.3109/01612840.2012.709585

Healey, A. N., Nagpal, K., Moorthy, K., \& Vincent, C. A. (2010). Engineering the system of communication for safer surgery. Cognition, Technology \& Work, 13(1), 1-10. doi:10.1007/s10111-010-0152-5

International Council of Nurses (2012). ICN Position: Patient Safety. Acedido em janeiro 30, 2016, em http://www.icn.ch/images/stories/documents/publications/position_statements/D05_Patient_Safety.pdf

Kerckhoffs, M. C., van der Sluijs, A. F., Binnekade, J. M., \& Dongelmans, D. A. (2013). Improving patient safety in the ICU by prospective identification of missing safety barriers using the bow-tie prospective risk analysis model. J Patient Saf, 9(3), 154-159. doi:10.1097/PTS.0b013e318288a476

Mendes, K.D.S.; Silveira, R.C.C. P.; Galvao, C. M. (2008). Revisão integrativa: método de pesquisa para a incorporação de evidências na saúde e na enfermagem. Texto contexto - enferm., Florianópolis, v. 17, n. 4. Acedido em abril 12, 2016, em http://dx.doi.org/10.1590/S0104-07072008000400018.

Mistry, N. K., Toulany, A., Edmonds, J. F., \& Matlow, A. (2010). Optimizing physician handover through the creation of a comprehensive minimum data set. Healthc Q, 13 Spec No, 102-109.

Pereira, A.S., Gaspar, C., Reis, D., Barradas, J., \& Nobre, P. (2012). Revisão sistemática de literatura. (VI Curso de Pós-Licenciatura de Especialização e III Mestrado em Enfermagem Médico-Cirúrgica). Coimbra: Escola Superior de Enfermagem de Coimbra.

Roque, Melo ECP. Avaliação dos eventos adversos a medicamentos no contexto hospitalar. Esc. Anna Nery. 2012 jan/mar; 16(1):121-7. 
eISSN: $2357-1330$

Selection \& Peer-review under responsibility of the Conference Organization Committee

Symons, N. R., Almoudaris, A. M., Nagpal, K., Vincent, C. A., \& Moorthy, K. (2013). An observational study of the frequency, severity, and etiology of failures in postoperative care after major elective general surgery. Ann Surg, 257(1), 1-5. doi:10.1097/SLA.0b013e31826d859b

Sousa, P., Uva, A.S., Serranheira, F., Leite, E. \& Nunes, C. (2011). Segurança do doente: eventos adversos em hospitais portugueses: estudo piloto de incidência, impacte e evitabilidade. Lisboa: Escola Nacional de Saúde Pública.ISBN 978-989-97342-0-3, p.13. 